\title{
The partial reinforcement effect sustained through blocks of continuous water reinforcement
}

\author{
MITRI E. SHANAB, SAIMI MELROSE, and TED YOUNG \\ California State University, Fresno, California 93740
}

\begin{abstract}
Thirsty rats received either partial or continuous water reinforcement in Phase I. In Phase II, half of the partially rewarded subjects were shifted to continuous reinforcement while the other half continued to receive partial reinforcement. The continuously reinforced subjects continued to receive the same reinforcement conditions as before. In Phase 3, all subjects underwent extinction. The results showed both a highly significant PREE and a sustained PREE. The need for investigation of known behavioral phenomena as a function of different reinforcers was emphasized.
\end{abstract}

One of the most reliable phenomena in psychology is that of the partial reinforcement extinction effect (PREE). Subjects receiving partial reinforcement in acquisition typically display slower extinction performance than comparable subjects receiving continuous reinforcement in acquisition. This phenomenon has been consistently found in a great number of studies carried out in different laboratories and with different species (Lewis, 1960; Robbins, 1971; Mackintosh, 1971). Yet, the ubiquitous PREE in instrumental learning situations has been challenged on two occasions. Earlier studies have found that in within-subjects designs, the conventional PREE is either reversed (Pavlik \& Carlton, 1965; Pavlik, Carlton, \& Hughes, 1965) or absent (Amsel, Rashotte, \& McKinnon, 1966; Rashotte \& Amsel, 1968; Rudy, Homzie, Cox, Graeber, \& Carter, 1970). However, the PREE was found in subsequent investigations of the within-subjects design (Pavlik, Carlton, \& Manto, 1965; Rashotte, 1968; Waters \& Knott, 1970). Recently, Macdonald and Toledo (1974) provided the second challenge to the generality of the PREE by showing that no PREE was obtained under water reinforcement conditions. Although few studies have used water reinforcement, Macdonald and Toledo cite, with reservations, three such studies in which a between-subjects PREE has been obtained (Gray, Quintâo, Araujo-Silva, 1972; Jenkins \& Rigby, 1950; King, 1972). However, a reliable PREE based on water reinforcement in the runway had already been reported by Wilson, Weiss, \& Amsel (1955). Feider (1973), using a within-subjects design, failed to find a PREE based on water reinforcement. This result is consistent with the food studies cited earlier, in which the PREE was also difficult to obtain in within-subjects designs.

The lack of a between-subject PREE water reinforcement (Macdonald \& Toledo, 1974), supports the recent admonitions made by several investigators concerning the generality of learning laws and principles

Reprint requests should be sent to Mitri E. Shanab, Psychology Department, California State University, Fresno, California 93740.
(Halliday \& Boakes, 1972; Hearst \& Jenkins, 1974; Seligman, 1970; Shettleworth, 1972). However, in view of the rather solid empirical base of the PREE, it is probably premature to conclude on the basis of one study that the PREE does not occur when water is used as the reinforcer. There were a few unorthodox procedures (to be discussed later), used by Macdonald and Toledo, that could account for the absence of the PREE. Prior to the Macdonald and Toledo study, the only known published study which reported an absence of a PREE based on water reinforcement was a study by Feider (1973) which was a within-subjects design. As stated earlier, the results could, among many things, be a function not of the type of reward but of the particular design used. Obviously, more investigations of this phenomenon using a within-subjects design are needed before any generalizations can be made. The present study was primarily designed to replicate and extend the findings of Macdonald and Toledo by using a sustained PRE paradigm and more conventional procedures such as using a $23 \frac{1}{2}-\mathrm{h}$ water deprivation as opposed to the 47-h water deprivation used by Macdonald and Toledo and running the subjects every day instead of every other day.

\section{METHOD}

\section{Design}

The subjects were randomly assigned to either a PR (50\%) or CR (100\%) water reinforcement schedule in Phase 1. In Phase 2, half of the PR subjects were shifted to CR (Group P-C), while the other half remained on the same PR schedule (Group P-P); the CR subjects (Group C-C) continued on the same reinforcement schedule. In Phase 3 , all groups underwent extinction.

\footnotetext{
Subjects

The subjects were 30 naive male albino rats of the Sprague-Dawley strain, approximately 90 days old at the start of the experiment.
Apparatus
A standard Hunter runway was used. The runway was modified in two ways: First, the guillotine doors separating the




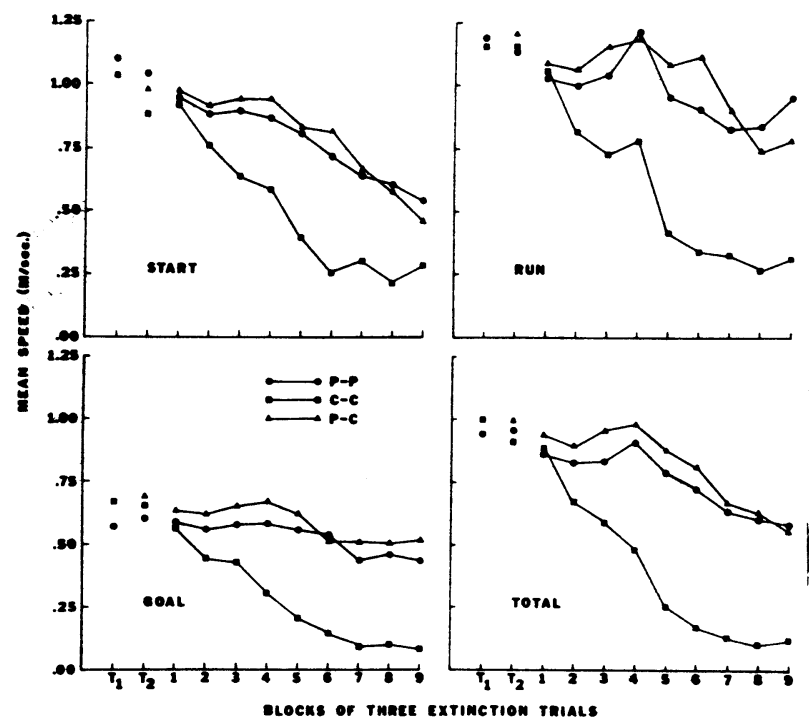

Figure 1. Mean start, run, goal, and total speeds in extinction. $T_{1}$ and $T_{2}$ stand for the mean running speeds over the last three blocks of Phases 1 and 2, respectively.

start from the run and the run from the goal sections were converted from electrical to manual operation. Second, a black self-sticking plastic coating covered the sides and ends of the runway from the outside. The top remained clear Plexiglas.

Four photocells were used to record start, run, and goal times. The first photocell was located $8 \mathrm{~cm}$ into the runway from the start door. The second photocell was located $25 \mathrm{~cm}$ beyond the first, while the third photocell was placed $100 \mathrm{~cm}$ beyond the second photocell. The distance between the fourth and the third photocells was $25 \mathrm{~cm}$ and the reinforcer cup was placed $8 \mathrm{~cm}$ into the goalbox. The photocells were connected to electric timers which measured time to the nearest $.01 \mathrm{sec}$.

The lighting was supplied by two $25-\mathrm{W}$ red light bulbs placed approximately $1.5 \mathrm{~m}$ over (but not directly above) the runway.

A clear plastic furniture coaster was used as the reinforcer cup; the coaster was $3.2 \mathrm{~cm}$ in diam and $6.3 \mathrm{~mm}$ deep. The water was placed in the reinforcer cup by means of a needleless hypodermic syringe which also served to measure the magnitude of the water delivered. Flush with the floor of the goalbox, a slot was made in the far wall through which the reinforcer cup was inserted.

\section{Procedure}

Upon arrival from the supplier, the subjects were housed individually and received food and water ad lib for 17 days. During this time, the subjects were handled and weighed daily. Twelve days prior to Phase 1 , all subjects were adapted to a $23 \frac{1}{2}-\mathrm{h}$ water deprivation schedule which was maintained throughout the study. This was done by allowing each subject $1 / 2 \mathrm{~h}$ daily access to water in the home cages. Four days prior to Phase 1, all subjects received $2 \mathrm{~min}$ free exploration of the unbaited runway with all equipment off and doors up. On the following day, all subjects received $1 \mathrm{~min}$ free exploration with the various equipment on. Immediately following removal from the runway, each subject was placed in the goalbox and given $1 \mathrm{cc}$ of water, which was the reinforcer magnitude used in acquisition. Throughout the experiment, each subject was given $1 / 2-h$ access to water in the home cage approximately $1 / 2 \mathrm{~h}$ after it had been run.

On Day 1 of Phase 1, all subjects received a single reinforced trial. On Day 2, two trials were given. The subjects in the CR schedule received two reinforced trials while those in the PR condition received one reinforced trial followed by one nonreinforced trial. On Day 3 and thereafter, all subjects received three trials per day and were run in squads of three with an ITI of approximately $3 \mathrm{~min}$. The 50\% PR schedule was determined randomly for the PR subjects with the restriction that no more than two reinforced or nonreinforced trials occurred in a row. All PR subjects were confined $15 \mathrm{sec}$ in the goalbox on nonreinforced trials. This phase was continued for 14 days (42 trials).

In Phase 2, the subjects in the PR condition were matched on runway performance and divided into two equal groups, (P-P and P-C). The P-C subjects were shifted to a continuous reinforcement schedule while the P-P subjects continued to receive the same intermittent schedule as before. The subjects in the C-C condition also continued to receive continuous reinforcement as in Phase 1. Phase 2 lasted 23 days (69 trials) with an ITI of approximately $3 \mathrm{~min}$. In Phase 3, all three groups underwent extinction. In the event that any subject refused to traverse any particular section of the runway within $30 \mathrm{sec}$, that subject was gently pushed into the goalbox, and a latency of $30 \mathrm{sec}$ was recorded for that and all subsequent sections of the runway. Extinction lasted 9 days ( 27 trials); all subjects were confined for $15 \mathrm{sec}$ in the empty goalbox. Throughout the study, start, run, and goal times were recorded and converted to reciprocals for later analysis.

\section{RESULTS}

All analyses are based on speed measures (meters/second). Analysis of the data in Phase 1 revealed that no crossover effect was present in any of the four sections of the runway, all $\mathrm{Fs}(13,364)<1$, for the interactions of treatments with blocks. The treatments effect was also nonsignificant, all $\operatorname{Fs}(1,28)<1$. However, the blocks effect was highly significant, $\mathrm{Fs}(13,364)=26.13,20.69,30.18$, and 36.71 , all ps $<.0001$ for start, run, goal, and total speed, respectively, indicating a clear acquisition effect. There were no discernible differences between the groups throughout Phase 2. The results of separate analysis of variance tests with repeated measures performed on terminal speed performance (last three blocks) in Phasees 1 and 2, reflected stable performances in all measures. For Phase 1, neither the blocks effect $[\operatorname{Fs}(1,28)=.002,2.19,1.66$, and 2.06 , all ps $>.05]$ for start, run, goal, and total speed, nor the interaction of blocks with treatments was significant [all Fs $(2,56)<1$ ] . Almost identical results were obtained in Phase 2. The main effect of treatments over the last three blocks of Phases 1 and 2 were similarly not significant, $F s(1,28)<1$ for start, run, and total speeds; and $F(1,28)=3.24, p>.05$ for goal speed for Phase 1 , and all $\operatorname{Fs}(2,27)<1$ for all four measures of Phase 2.

As Figure 1 shows, all four speed measures were highly similar in showing a more rapid decrease in speed for the C-C subjects relative to the P-P and P-C subjects. This was supported by the highly significant Treatments by Blocks interaction effects, $\operatorname{Fs}(16,216)=2.33,2.58$, 3.91 , and 3.77 ; ps $<.004, .001, .0001$, and .0001 for start, run, goal, and total speed, respectively. The blocks effect was also significant, $\operatorname{Fs}(8,216)=30.62,12.1 \mathrm{r}$ 
17.94 , and 27.58 ; all ps $<.0001$, for start, run, goal, and total speed, respectively. Except for the start speed, which barely reached significance, $F(2,27)=3.28$, $\mathrm{p}=.052$, the treatments effect was highly significant, $\operatorname{Fs}(2,27)=6.75,24.37$, and 10.23 , all ps $<.005$ for run, goal, and total speed, respectively. Using the total speed as representative of the other three speeds, individual comparisons were made which yielded highly significant results for the difference between the continuously reinforced group and the two partially reinforced groups, $\mathrm{t}(18)=4.12$ and 4.31 , both $\mathrm{ps}<.005$, for the P-P vs. C-C and the P-C vs. C-C comparisons, respectively. The difference between the P-P and P-C groups was not significant, $t(18)<1$.

\section{DISCUSSION}

The results of the present study are clear in showing that not only does the PREE occur with water reinforcement but that it is not attenuated by the insertion between acquisition and extinction of a large number of continuously reinforced trials. In both cases, the effect was very strong. The obtained PREE agrees with the many studies using either food (Robbins, 1971) or sucrose reward (Likely, Little, \& Mackintosh, 1971; Tombaugh, McCloskey, \& Tombaugh, 1971), as well as with the water studies cited earlier (Gray et al, 1972; Jenkins \& Rigby, 1950 King, 1972; Wilson et al., 1955). The sustained PRE obtained in this study supports and extends similar findings obtained with food reward (Jenkins, 1962; Leung \& Jensen, 1968; Sutherland, Mackintosh, \& Wolf, 1965; Theios, 1962). Until now, no investigation of sustained PRE as a function of water reward seems to have been carried out.

The discrepancy in results between this study and that of Macdonald and Toledo could be attributed to several procedural differences. Macdonald and Toledo used a very small magnitude of water reinforcement. With small food reward, either a very weak or no PREE is obtained (Amsel, 1958; Gonzalez \& Bitterman, 1969; Hulse, 1958; Roberts, 1969; Wagner, 1961; Yamaguchi \& Sukenmune, 1963). The finding of no PREE by Macdonald and Toledo was based on the analysis of start and run times, not on speeds; no goal times were reported. In the first place, it is customary in runway studies to transform the raw data (time or latency) to reciprocal or speed measures in order to normalize the distribution and meet one of the basic assumptions of such a parametric test as the analysis of variance test. Macdonald and Toledo did not transform the latency data but nevertheless used the analysis of variance test to analyze their results. It is conceivable that the absence of the PREE could have been an artifact of the statistical analysis used. For example, one or two very slow rats in the partially reinforced group could have produced the effect. In the second place, the goal speed is usually a more sensitive extinction measure than the start or run speeds, as is shown in this and many similar PRE studies. Moreover, both the intertrial (ITI) and the intersession (ISI) intervals used in this study, $3 \mathrm{~min}$ and $24 \mathrm{~h}$, respectively, were considerably shorter than the $15-\mathrm{min}$ ITI and 47 -h ISI used by Macdonald and Toledo. Spaced trials have been reported to decrease resistance to extinction (cf. Capaldi, Berg, \& Sparling, 1971; Mackintosh, 1970). It is possible that the combined effects of long ITIs and ISIs attenuate the PREE, thus accounting for the failure of obtaining a PREE in the Macdonald and Toledo study.

Yet investigations of the effects of water reinforcements on known behavioral phenomena need to be encouraged since the vast majority of our behavioral principles are based on food reinforcement, a few on sucrose, and a negligible part on water reinforcement. Thus, there is an appallingly small number of studies which investigated the PREE as a function of water reward. Besides the limitations pointed out by Macdonald and Toledo concerning the three studies which obtained a PREE with water reward, only the study by Jenkins and Rigby (1950) which used a Skinner box can be considered a bona fide traditional PRE study. Although the other two studies used the runway, the PREE reported by Gray et al. (1972) was based on a comparison of sham-operated PR and CR subjects. It is not known how the surgical effects interact with the type of reward. The second study (King, 1972) is equally difficult to interpret since, prior to the schedule manipulation, the subjects were subjected to an approach-avoidance conflict which was induced by adding a bitter-tasting substance to the water reward. Apparently, the evidence for a traditional PREE with water reward is based on the results of only three studies, namely, those showing response-rate differences (Jenkins \& Rigby, 1950), respsonse frequency differences (Wilson et al., 1955), and those showing speed differences as in the present study.

Current PRE explanations (cf. Amsel, 1958; Capaldi, 1967) can easily account for the present findings. However, for a more thorough understanding of the PRE and other behavioral phenomena, considerably more studies using water and other nonfood reinforcers need to be carried out.

\section{REFERENCES}

AMSEL, A. The role of frustrative nonreward in noncontinuous reward situations. Psychological Bulletin, 1958, 55, 102119.

Amsel, A., Rashotte, M. E., \& MacKinnon, J. R. Partial reinforcement effects within subjects and between subjects. Psychological Monographs, 1966, 80, (20, Whole No. 628).

Capaldi, E. J. A sequential hypothesis of instrumental learning. In K. W. Spence \& J. T. Spence (Eds.), Psychology of learning and motivation. New York: Academic Press, 1967.

Capaldi,. E. J., Berg, R. F., \& Sparling, D. L. Trial spacing and emotionality in the rat. Journal of Comparative and Physiological Psychology, 1971, 76, 290-299.

FEIDER, A. Within subjects partial reinforcement extinction effects for a bar pressing task. Canadian Journal of Psychology, 1973, 27, 356-366.

Gonzalez, R. C., \& Bitterman, M. E. Spaced-trials partial reinforcement effects as a function of contrast. Journal of Comparative and Physiological Psychology, 1969, 67, 94-103.

Gray, J. A., Quintấ, L., \& Araujo-Silva, M. T. The partial reinforcement extinction effect in rats with medial septal lesions. Physiology and Behavior, 1972, 8, 491-496.

Halliday, M. S., \& Boakes, R. A. Discrimination involving response-independent reinforcement: Implication for behavioral contrast. In R. A. Boakes \& M. S. Halliday (Eds.), Inhibition and learning. New York: Academic Press, 1972. Pp. 73-97.

Hearst, E., \& Jenkins, H. M. Sign-tracking: The stimulusreinforcer relation and directed action. Psychonomic Society Monograph, 1974, 1-49.

Hulse, S. H. Amount and percentage of reinforcement and duration of goal confinement in conditioning and extinction. Journal of Experimental Psychology, 1958, 56, 48-57.

Jenkins, H. M. Resistance to extinction when partial reinforcement is followed by regular reinforcement. Journal of Experimental Psychology, 1962, 64, 441-450.

Jenkins, W. O., \& Rigby, M. K. Partial (periodic) versus continuous reinforcement in resistance to extinction. Journal of the Experimental Analysis of Behavior, 1973, 20, 163-182.

KING, M. G. Inhibition, reacquisition and extinction of approachavoidance conflict. Journal of Experimental Psychology, 1972, 92, 360-364. 
Leung, C. M., \& Jensen, G. D. Shifts in percentage of reinforcement viewed as changes in incentive. Journal of Experimental Psychology, 1968, 76, 291-296.

LEWIS, D. J. Partial reinforcement: A selective review of the literature since 1950. Psychological Bulletin, 1960, 57, 1-28.

Likely, A., Little, L., \& Mackintosh, N. J. Extinction as a function of mangitude and percentage of food or sucrose reward. Canadian Journal of Psychology, 1971, 25, 130-137.

Macdonald, G. E., \& Toledo, L. Partial reinforcement effects and type of reward. Learning and Motivation, 1974, 5, 288-298.

Mackintosh, N. J. Distribution of trials and the partial reinforcement effect in the rat. Journal of Comparative and Physiological Psychology, 1970, 73, 341-348.

Mackintosh, N. J. Partial reinforcement and extinction. In N. S. Sutherland \& N. J. Mackintosh (Eds.), Mechanisms of animal discrimination learning. New York: Academic Press, 1971. Pp. 338-429.

Pavlik, W. B., \& Carlton, P. L. A reversed partial reinforcement effect. Journal of Experimental Psychology, 1965, 70, 417-423.

Pavlik, W. B., Carlton, P. L., \& Hughes, R. A. Partial reinforcement effects in a runway: Between- and within-subjects. Psychonomic Science, 1965, 3, 203-204.

Pavlik, W. B., Carlton, P. L., \& Manto, P. G. A further study of the partial reinforcement effect within subjects. Psychonomic Science, 1965, 3, 533-534.

Rashotte, M.E. Resistance to extinction of the continuously rewarded response in within-subject partial-reinforcement experiments. Journal of Experimental Psychology, 1968, 76, 206-214.

Rashotte, M. E., \& Amsel, A. The generalized PRE: Within-S PRE and CRF training in different runways, at different times of day, by different experimenters. Psychonomic Science, 1968, 11, 315-316.

Robbins, D. Partial reinforcement: A selective review of the alleyway literature since 1960. Psychological Bulletin, 1971, 76, 415-431.

RoBERTS, W. A. Resistance to extinction following partial and continuous reinforcement with varying magnitudes of reward. Journal of Comparative and Physiological Psychology, 1969, 67, 395-400.
Rudy, J. W., Homzie, M. J., Cox, R. D., Graeber, R. C., \& CARTER, E. N. Effects of sequential manipulations in the within-subjects partial reinforcement runway experiment with rats. Journal of Comparative and Physiological Psychology, 1970 , 72, $105-115$.

Seligman, M. E. P. On the generality of the laws of learning. Psychological Review, 1970, 77, 406-418.

SheTtLewORTh, S. J. Constraints on learning. In D. S. Lehrman, R. A. Hinde, \& E. Shaw (Eds.), Advances in the study of behavior (Vol. 4). New York: Academic Press, 1972. Pp. 1-68.

Sutherland, N. S., Mackintosh, N. J., \& Wolfe, J. B. Extinction as a function of the order of partial and consistent reinforcement. Journal of Experimental Psychology, 1965, 69. 56-59.

Theios, J. The partial reinforcement effect sustained through blocks of continuous reinforcement. Journal of Experimental Psychology, 1962, 64, 1-6.

Tombaugh, J., McCloskey, J. L., \& Tombaugh, T. N. Delayed partial reinforcement effect. Canadian Journal of Psychology, 1971, 25, 419-426.

WAGNER, A. R. Effects of amount and percentage of reinforcement and number of acquisition trials on conditioning and extinction. Journal of Experimental Psychology, 1961, 62, 234-242.

WATERS, W., \& KNOTT, P. D. Tests of frustration theory extended to the generalized PRE. Psychonomic Science, 1970, 20, 61-62.

Yamaguchi, M., \& Sukenmune, S. Effects of total amount of reinforcement under partial reinforcement schedules on running speeds. Japanese Psychological Research, 1963, 5, 137-141.

Wilson, W., Weiss, E. J., \& Amsel, A. Two tests of the Sheffield hypothesis concerning resistance to extinction, partial reinforcement, and distribution of practice. Journal of Experimental Psychology, 1955, 50, 51-60.

(Received for publication May 27, 1975.) 